\title{
A Cross-Case Analysis of Innovation Platform Experiences in Seven Countries in West and East Africa and South Asia
}

\author{
Emmanuel S. Monyo, Essegbemon Akpo, Chris O. Ojiewo, \\ and Rajeev K. Varshney
}

\section{Abstract}

The Bill and Melinda Gates Foundation (BMGF) funded Tropical Legumes (TL III) project was implemented in seven sub-Saharan Africa countries (Burkina Faso, Ghana, Mali, Nigeria, Ethiopia, Tanzania, and Uganda) and South Asia (India). Shortage of seed of improved varieties has been identified as the greatest hindrance to farmer adoption of new agricultural technologies developed through this project. This chapter compares the different approaches followed by different countries in the establishment of Multi-Stakeholder Platforms (MSPs) for supply of improved legume seed to farmers. Achievements from this initiative are mixed and multi-dimensional. The details herein provide the reader with insights on the level of success of innovation platforms in the different countries and implications for agricultural technology dissemination to smallholder farmers. Key achievements include strengthened linkages among various legume seed value chain actors, participation of several cadres of seed producers in a decentralized system resulting into significant increase in the production of certified and quality declared seed of legumes, and rapid adoption and use of newly

\footnotetext{
E. S. Monyo $(\square)$

Alssem Company Limited, Arusha, Tanzania

e-mail: emonyo@alssem.com

E. Akpo · C. O. Ojiewo

International Crops Research Institute for the Semi-Arid Tropics (ICRISAT), Nairobi, Kenya

R. K. Varshney

Research Program - Genetic Gains, International Crops Research Institute for the Semi-Arid Tropics (ICRISAT), Patancheru, India
} 
released varieties by smallholder farmers. As for those areas where the initiative did not produce the desired results, it is a testament that unless a well thought-out inclusive and comprehensive approach which defines the critical roles of each player in the value chain is developed, current seed shortages will continue, eroding emerging market opportunities and good intentions of development partners. The reader is directed to individual chapters for details of the process followed by each country/crop in the establishment of MSPs, their composition, key achievements, challenges, and lessons for overall improvement of the national legume seed systems.

\section{Keywords}

MSPs · Tropical Legumes III project · Improved variety seed · Legume value chain $\cdot$ Seed systems

\subsection{Introduction}

Smallholder legume farmers, who tend to dominate the legume production sector, have many times cited lack of access to quality seeds of adapted and improved varieties as a major constraint to improving their productivity and production. Preliminary research results from the Tropical Legumes (TL II) baseline studies in all project countries found that there was very limited awareness about improved legume varieties, and that neither public- nor private-sector interventions to produce and market legume seeds had a successful track record (Ndjeunga et al. 2016). Most of these smallholders rely on own-saved seed or seed secured through informal networks such as local grain markets or farmer-to-farmer exchanges. Scholars reported that less than $10 \%$ of the crop seed planted in Africa is purchased from the formal market each year (Rohrback et al. 2003; McGuire and Sperling 2016). Generally, the traditional seed certification procedures do not facilitate the use of quality seed of improved legume varieties by the majority of resource-poor farmers who source about $90 \%$ of their seed from the informal sector (McGuire and Sperling, 2016). Although cheap and easily accessible, these informal seed sources may compromise quality, tolerance/resistance to pests and diseases and subsequent productivity. This is the reason why Quality Declared Seed (QDS) has been scaled up in most countries but at the same time catalyzing private companies' investments.

Pilot interventions through the Tropical Legumes Projects (TL II and TL III) have shown promise in making new varieties available to farmers who depend on the farmer seed system. These initiatives which included community seed schemes, seed recovery and seed bank schemes, seed fairs, contracting schemes, and small seed packs were further developed, and linked to participatory research, where farmers are directly involved in variety selection and testing. Since 2007 and through the BMGF funded Tropical Legumes projects, more than 21,000 farmer/legume seed producers (11,000 in Tanzania, 5535 in Uganda, 2300 in Ethiopia, 1381 in 
Kenya, 677 in Malawi, and 860 in Mozambique) participated in a total of 171 farmer field days and 27 farmer fairs held on-farm and on-station (Gowda et al. 2014). If farmers want to compete in the global marketplace, their produce must meet the grades and standards desired by end-users. R\&D agencies linked through TL III implementation have designed and tested several demand-driven seed supply strategies, which provide the necessary incentives for farmers to buy seed from the recommended sources (Rubyogo et al. 2019).

This approach was implemented in partnership with a range of organizations- to improve seed supply of legume varieties and create impact at farm level. It is based on two propositions; that different approaches are required for different crops and countries, and, that we must lay greater emphasis on stimulating seed demand rather than focusing exclusively on seed supply. Multi-stakeholder platform has been acknowledged as one of the means to get such partnerships shaped and operational. Through location specific innovation platforms, most of which have been formed and supported by the TL III project, collaborative networks of public-private sector stakeholders and development organizations in the legume value chain have been formed to bring together relevant partners that contribute to the efficient flow of information and seed between target stakeholders. The networks then share evidence on best practices, innovative ideas, and problem-solving expertise across their legume crops of interest, share facilities and services among those best equipped to carry out different tasks, coordinate and foster inter-disciplinary and cross-crop collaboration, mentor and train one another as they share ideas and their success stories, and create a consensus of opinion to informed practices and policy-making.

Having shared the experiences of various countries in the previous chapters, a synoptic look across the various chapters is provided in this chapter to draw the similarities and differences among countries and crops. Beyond a synthesis of all cases, this chapter presents the reader with the big picture arising from the experiences of different TL III countries with innovation platforms for legumes' seed supply to smallholder farmers, especially the ones in remote areas facing ever challenging production environment.

\subsection{Overview of Country Approaches, Achievements, and Key Lessons}

\subsubsection{Cowpea and Groundnut Innovation Platform Interventions in Burkina Faso}

Lack of access to seed of improved varieties is a significant constraint to farmer adoption of new agricultural technologies in Burkina Faso. The INERA cowpea team recognized this constraint and through the support of TL III project established four multi-stakeholder innovation platforms-one for each region for enhancing cowpea production and productivity in the country. Through the platform established in 2015, more than 200 targeted farmers were trained in different areas of the 
cowpea value chain including seed and grain production, storage, and food processing skills. Through the platform, new cowpea varieties were disseminated through demonstration plots, field days, mass media, and social media. Each platform was supported to produce a minimum of 10 ha basic seed. As a result of the growing need for basic seed in the country and INERA's inability to meet this need, the more progressive out of the four platforms was identified and contracted to supply INERA's balance of basic seed requirement. This was pivotal in building sustainability of basic seed supply through the platforms as a result of the official link to fill INERA's deficit. By 2018, basic seed production through the platforms had peaked to 1000 metric tons per year. Following on the success of the cowpea team, groundnut innovation platforms were similarly established in the country from 2016. For the first time, farmers in the country were supplied with Quality Declared Seed (QDS) as a result of this initiative. By 2018, more than 10,000 farmers were reached with improved seed supplied through small seed packs annually, and farmer yields for groundnut had increased from $500-700 \mathrm{~kg} / \mathrm{ha}$ to $1200-1500 \mathrm{~kg} / \mathrm{ha}$. Women and youth incomes from the project areas increased from US\$200 to 800 per year for farmers who utilized the rainy season only, but for those who got two seasons by supplementing with irrigation had their incomes increased to US\$1200-1500 per year. The platform successes were as a result of linkages to financial institutions for credit to farmers. Since farmers had increased incomes, they were able to service their loans and could continue accessing this facility. INERA was further facilitating sustainability of these platforms through introduction of annual membership contribution fees which the farmers are willing to pay since they are benefiting.

\subsubsection{Enhancing Access to Quality Seed of Improved Groundnut and Cowpea Varieties Through Multi-Stakeholder Platforms in Northern Ghana}

In spite of release of new varieties of cowpea and groundnuts in Ghana, for years, yields under farmer conditions remained low (0.5-0.8 t/ha) compared to more than 1.5-2.5 tons attained with improved varieties released by the national system. The main reason for this is the unavailability of seed of these improved varieties for farmers. Less than $5 \%$ of the crop is cultivated with certified seed purchased from the formal seed system, while the rest is sourced from farmers' saved seeds, gifts from family and friends and the grain market, often of questionable quality. Farmers' failure to use new varieties has been attributed to the inaccessibility and highly priced nature of seed in the formal system. Through use of funds from TL III project, the groundnut and cowpea research teams established MSPs for supply of improved variety seed and related agricultural technologies to farmers. Platform composition included famers (over 70\%), agro-input dealers, processors, traders, tractor service providers, research and extension. Though financial services were missing, each MSP built in a savings and loan scheme as a self-help funding mechanism. Eight MSPs were formed between 2015 and 2016 with membership totaling 
347 for groundnut and 820 for cowpea. Key achievements under groundnut included an injection of at least 5 tons seed of the new improved varieties into the community annually. This resulted into a 70\% increase in yields among platform farmers compared to those who were not being served. Similarly, the cowpea platforms trained members to produce certified seed for supply to their communities. More than 1800 members were trained in various farm operations including good agronomic practices that have managed to sustain continued availability of improved variety seed among platform members.

\subsubsection{Cowpea and Groundnut Seed Innovation Platforms: A Hope for Small Seed Producers in Mali}

Groundnut and cowpea are the most important legume crops in Mali contributing to food security and family incomes. The research system has developed and released several improved varieties but most of them have remained on the shelf due to the inadequacy of the seed supply system to the extent of reflecting a national decline in groundnut production. This constraint was identified by the groundnut team who decided to reverse the decline curve through establishment of the Kolokani MSP in 2012. Through additional resources from TL III, the platform was reorganized in 2015 to include more stakeholders representing the entire groundnut value chainfarmers, farmer associations, cooperative societies, seed producers, agro-dealers, transporters, financial services, grain traders, processors, research and extension. Variety promotional activities included 47 farmer participatory variety selection (FPVS), 50 demonstration plots, and three multi-locational variety trials conducted annually from 2016 to 2018. Two out of four released varieties in Mali (Fleur 11 and ICGV 86124) were identified through the FPVS and promoted through training of trainers to 1246 farmer seed producers; among them 928 women. Platform members and farmers were also trained in groundnut seed production, aflatoxin management, seed business plans, and small-scale mechanization to reduce drudgery and improve efficiency in production. Kolokani platform is capable of producing and marketing more than 85 tons of groundnut certified seed to farmers in Mali each year. This is expected to reverse the national productivity decline while improving platform members' livelihoods and family nutrition status. Similarly, an innovation platform for cowpea value chain players was established at Cinzana following availability of resources from the TL III project in 2016. Building on the groundnut platform, they added a program planning committee and an executive office so that feedback from stakeholders can receive immediate attention. Notable achievements through the cowpea platform included an increase in promotional activities - 25 training sessions, 299 demonstration plots, involving 2934 cowpea seed producers and benefiting 12,193 farmers. The number of farmer preferred varieties used increased from 5 to 12, while the amount of basic seed produced increased annually from 1 to 20 tons serving more farmers through affordable small seed packs. 


\subsubsection{Sustainable Groundnut and Cowpea Seed Systems for Smallholder Farmers Though Innovation Platforms in Nigeria}

MSPs for supply of improved seed of groundnut and cowpea to farmers were implemented in Nigeria in 2015 as part of the TL III project. Since the main purpose of the project was to improve the production and productivity of legumes in the country (namely cowpea and groundnut), it was clear that availability of seed of improved varieties was one of the greatest constraints to delivering on the project. MSPs were, therefore, established in specific project locations as part of facilitating the access of smallholder farmers to seeds of improved varieties. Members of the MSPs included seed companies, farmer groups, public seed enterprises, NGOs, and 718 individual seed entrepreneurs to link actors in the legumes' value chains. Community-based seed producers and individual entrepreneurs were linked to seed companies while seed companies were linked to financial services for seed purchase loans and to research institutions to access early generation seed (EGS) for supply to their contract growers. The results were phenomenal. There was a marked increase in access by farmers to services (e.g., improved variety seeds, extension, credit facilities, and markets) and enhanced production and productivity through increased availability of quality seed, increased farm size, and yields. About 532 tons of basic seed and 8366 tons of certified/QDS seed of improved cowpea were availed to farmers. Cowpea yields almost doubled from 500 to $900 \mathrm{~kg} / \mathrm{ha}$ in the project intervention areas. MSP members for groundnut recorded additional incomes ranging from $\$ 214$ to 453 per hectare in the wet season and $\$ 193$ to $\$ 823$ per hectare in the dry seasons as a result of project intervention through MSPs. Due to better farmer organization for collective marketing, farmers were able to improve their produce markets prices by $21.5 \%$ and $18 \%$ for dry and wet season groundnut production, respectively. Selection of appropriate project location, reliable well-connected beneficiaries, timely supply of agricultural inputs, training on good agronomic practices (GAPs), and effective supervision on production were the major drivers of success.

\subsubsection{Chickpea Production and Productivity Through Stakeholders' Innovation Platform Approaches in Ethiopia}

Ethiopia is the leading producer and consumer of chickpea in Africa (Kassie et al. 2010). The country is among the top 10 producers in the world where, chickpea is also an export crop earning the country the much needed foreign currency. In spite of its importance, national production has been rated as low and below potential as production is challenged by low productivity of landraces, poor farming practices, biotic and abiotic stresses, among others. The chickpea improvement program made considerable efforts to overcome the aforementioned constraints and developed 27 improved varieties and management technologies for their dissemination to farmers. This resulted in a paradigm shift of the Ethiopian chickpea production that progressed from landrace cultivars to improved varieties together with enhanced 
adoption of production packages recommended by research. Inspite of the achievements recorded, the speed with which positive changes were being effected remained slow and productivity low compared to potential. To correct the situation, a national chickpea stakeholders' innovation platform was established in 2013 with the main objective of bringing together the key stakeholders acting on the value chain in order to identify major challenges and craft solutions that would be implemented through synergetic efforts. The platform would provide space for interactions and collaboration within and between heterogeneous group of individuals comprising the agricultural research system, public institutions that support agricultural development, seed producers, farmers' primary cooperatives and unions, entities working on bio-fertilizer and storage management, food processors, and exporters to complement one another for the benefit of the chickpea value chain. The platform identified seed as the major bottleneck in the sector. This gave room to the agricultural research systems that supported the platform with a mandate to take steps to address the seed constraint through establishing farmers' seed producer associations with the help of R\&D partners. These farmer seed associations are currently the major suppliers of chickpea seed nationwide. Side by side, the platform strengthened the extension effort and triggered dissemination of improved technologies to a large number of farmers. As a result, productivity of the crop by model farmers increased by threefold and fourfold and the national productivity has been doubled to nearly 2 tons.ha ${ }^{-1}$. The platform also worked on improving access to market, and chickpea is currently one of the commodities in the Ethiopian Commodity Exchange market.

\subsubsection{Groundnut Seed Production and Distribution Through Multi-Stakeholder Platforms in the Southern Region of Tanzania}

Over $90 \%$ of Tanzania's groundnut production is confined to four important production corridors-namely The Southern (Mtwara, Lindi, and Ruvuma), Central (Dodoma and Singida), Western (Tabora, Igunga, and Nzega), and Lake (Shinyanga, Geita, and Mwanza) regions of the country. Groundnut seed systems innovation platform was established for the Southern region in 2016 to enhance farmer access to improved variety seed. The platform key players are representatives from government extension services, NGOs, seed companies, farmer groups, and individual seed entrepreneurs (53 in total, with $42 \%$ female representation). Notable achievements included an increase in the frequency of farm advisory services from extension mainly facilitated by project funds, including establishment of community extension services and lead farmer concept. Better access to improved seed in the target areas has resulted into $11 \%$ increase in area under cultivation and $15 \%$ increase in production by 2018 as compared to before. Most of this has been possible as a result of 29 labor-saving technologies that contributed to reducing women drudgery and therefore increased efficiency. The platform facilitated new market linkages that have helped improve farm gate prices by $80 \%$ putting more money into farmers' hands. Farmer improved varieties choice has also expanded from 3 
before the platform to 11 . Unfortunately, there are no linkages yet to financial institutions for facilitation of platform activities. Platform membership might need to include this cadre of stakeholders for it to be viable and sustainable.

\subsubsection{Organized Farmers Towards Chickpea Seed Self-Sufficiency in Bundelkhand Region of India}

India is the largest producer and consumer of chickpea globally growing the crop on 10.75 million hectares and producing 11.23 million tons annually. Bundelkhand region of Uttar Pradesh state where the TL III project was implemented is traditionally an important chickpea-growing region with 416,007 ha that produces about 148,408 tons of chickpea-very far below the national average $(0.35 \mathrm{vs} 1.04 \mathrm{t} / \mathrm{ha})$. Poor seed replacement and low productivity levels, high incidence of pod borer and root diseases coupled with several abiotic stresses limit the average chickpea productivity in the region. Smallholder farmers in the region often cite poor quality of seed as a major issue restraining the chickpea productivity level (Dixit et al. 2019). Farmers lack access to new high yielding, diseases resistant chickpea varieties. As a consequence, they continue to use farm produce of non-descript varieties as seed across, for all the major pulse crops. Farmers often exchange home-grown seeds with apparently better yielding varieties available within their informal social networks including fellow farmers, friends, and relatives. These factors have direct bearing on the chickpea productivity in the region (Dixit et al. 2019). To address the challenge of unavailability of quality seed of improved chickpea varieties, partner farmers under TL III project were organized into innovation platform with the objective of enhancing seed production, processing, and storage to ensure selfsufficiency at village level, promoting diffusion of seed production technologies; and dissemination of recommended and farmer preferred varieties. Through the seed societies, 21.8 tons improved seed of five recommended varieties were produced and marketed to institutionalized seed chains. More than 1500 partner farmers directly received improved variety seed from these societies, while 1788 non-partner farmers benefitted through social networks established as a result of this initiative. Chickpea productivity was boosted from 0.78 to $1.19 \mathrm{t} / \mathrm{ha}$ in the project villages. Area under improved chickpea varieties was increased by $68 \%$ in the project villages while putting in place a system for supply of improved chickpea seed which can be replicated in other districts throughout the country.

\subsection{Cross-Case Analysis, Reflection on Key Lessons, and Drivers of Success}

Agricultural innovation platforms are brought to play when systemic bottlenecks in the institutional arrangements make it difficult to bring about the changes needed. The critical challenge is that demand for innovation is low and therefore the driver which could push the delivery systems is weak. Under this scenario, most supply 
driven innovation approaches fail because the demand is low. The strategy is, therefore, to enhance the demand for innovation to make the system works better. In cognizance of this, partner countries implementing the TL III set out to establish innovation platforms for improved seed supply to solve the bottleneck of seed unavailability. The results were mixed. Some platforms picked up very well and are on their way to sustaining the seed supply chain while others are struggling and need constant hand holding and maybe redesign. Each country followed the following recommended (Ngwenya and Hagmann 2011) steps in establishing its IP and business models (Table 13.1) to some varying degree hence the variable outcomes as well.

In Burkina Faso Although the platforms engaged in local seed businesses, no seed business model was developed as a way of creating incentives for the system to know that stakeholders can operate profitably and therefore incentivized to continue. They however put in place financial contribution by each member after selling their produce in order to be able to facilitate platform meetings without external financial support. The accessibility of seeds of improved varieties by farmers at low price was the target through the platforms as well as to increase the income of women who are the largest groups among farmers.

Table 13.1 A comparative analysis of the steps towards establishing the innovation platforms, partnerships, and business models

\begin{tabular}{l|l|l|l|l|l|l|l}
\hline Steps & BF & GH & ML & NG & ET & TZ & IN \\
\hline $\begin{array}{l}\text { Definition of a problem with high opportunity for } \\
\text { impact }\end{array}$ & $\sqrt{ }$ & $\sqrt{ }$ & $\sqrt{ }$ & $\sqrt{ }$ & $\sqrt{ }$ & $\sqrt{ }$ & $\sqrt{ }$ \\
\hline $\begin{array}{l}\text { Formulation of the innovation challenge-defining the } \\
\text { scope and focus of the platform }\end{array}$ & $\sqrt{ }$ & $\sqrt{ }$ & $\sqrt{ }$ & $\sqrt{ }$ & $\sqrt{ }$ & $\sqrt{ }$ & $\sqrt{ }$ \\
\hline $\begin{array}{l}\text { Identification of the functions required to make the } \\
\text { system work as a system }\end{array}$ & $\sqrt{ }$ & - & - & $\sqrt{ }$ & $\sqrt{ }$ & & $\sqrt{ }$ \\
\hline $\begin{array}{l}\text { Identification of the actors who can best deliver these } \\
\text { functions effectively and efficiently }\end{array}$ & $\sqrt{ }$ & $\sqrt{ }$ & $\sqrt{ }$ & $\sqrt{ }$ & $\sqrt{ }$ & $\sqrt{ }$ & $\sqrt{ }$ \\
\hline $\begin{array}{l}\text { First meeting to analyze systemic blockages and first } \\
\text { actions. }\end{array}$ & $\sqrt{ }$ & $\sqrt{ }$ & $\sqrt{ }$ & $\sqrt{ }$ & $\sqrt{ }$ & $\sqrt{ }$ & $\sqrt{ }$ \\
\hline $\begin{array}{l}\text { Development of a compelling business model creating } \\
\text { the incentives of the system to work }\end{array}$ & - & - & - & - & - & - & - \\
\hline $\begin{array}{l}\text { Assessment of systemic capacity including each } \\
\text { individual actor's capacity and capacity development } \\
\text { needs identified to strengthen the core actors' capacity }\end{array}$ & - & $\sqrt{ }$ & - & $\sqrt{ }$ & $\sqrt{ }$ & - & - \\
\hline $\begin{array}{l}\text { Draw an action plan to start operating as a platform } \\
\text { towards delivery. }\end{array}$ & $\sqrt{ }$ & $\sqrt{ }$ & $\sqrt{ }$ & $\sqrt{ }$ & $\sqrt{ }$ & $\sqrt{ }$ & $\sqrt{ }$ \\
\hline $\begin{array}{l}\text { Review action, performance, and analysis in regular } \\
\text { intervals. }\end{array}$ & $\sqrt{ }$ & $\sqrt{ }$ & $\sqrt{ }$ & $\sqrt{ }$ & $\sqrt{ }$ & $\sqrt{ }$ & - \\
\hline $\begin{array}{l}\text { Continuously assess and enhance the performance of } \\
\text { the platform actors, including regular self-assessment } \\
\text { to enhance the platforms' performance }\end{array}$ & $\sqrt{ }$ & $\sqrt{ }$ & $\sqrt{ }$ & - & $\sqrt{ }$ & & $\sqrt{ }$ \\
\hline
\end{tabular}

$B F$ Burkina Faso, $G H$ Ghana, $M L$ Mali, $N G$ Nigeria, ET Ethiopia, TZ Tanzania, IN India 
In Ghana Poor consultation among MSP members and lack of clear-cut procedures on resolving conflicts were identified as major problems that needed to be prevented for the platform to smoothly operate as a system. Some members made up their minds to actively participate at meetings or to leave the group all together. These conflicts resulted from the fact that actors were drawn from different sectors of the groundnut value chain and as such had diverse views and sometimes conflicting interests. To address this challenge, a training on group dynamics was organized for members. The training was geared towards enabling actors to be more tolerant and positive towards diversity in order to promote a peaceful coexistence to ensure successful implementation of activities. Another big constraint was financial facilitation of platform activities. Members indicated that it was difficult getting money to plow their fields and buy the needed inputs such as seed and herbicides. Although there are rural banks and savings and loans institutions in many areas, high cost of borrowing and demand for collateral was a disincentive to many farmers. More so, these institutions are of the view that smallholder farming is a very risky business resulting in one of the highest interest rates applied (about $40 \%$ p.a) when lending to actors in agriculture. To address this challenge of funding, the platforms were introduced to and adopted the Village Savings and Loans Association (VSLA) concept. This self-help microfinance initiative was rolled out to help group members put monies together through weekly savings.

In Mali The cowpea and groundnut platforms followed similar approaches, but platform members dropped out for cowpea. The seed companies, Agro-dealers, microfinance, and transporters all dropped out because of low opportunities in commercialization of cowpea seeds. Fortunately, the same remained intact with the groundnut platform but the seed problem was far from over. Improved seed production has had its ups and downs. Today we cannot say that the end of the tunnel is reached because many problems remain unresolved. The price of seed is still high and out of reach of many smallholder farmers. It is still difficult to access financial credit for seed production and productivity is still low due to low levels of mechanization. Certainly, some efforts were made by the platform and its partners through TL III. Insufficiency, access, and price of certified seeds can be solved by expanding the production to farmer organizations and private organizations in partnership with research. As a perspective, the Kolokani platform adheres to the idea of creating a national platform to solve the improved variety seed constraint. The community of Kolokani has moved from traditional groundnut production to more businessoriented production as a result of the platform boosting groundnut farming culture while winning the fight against poverty among the masses and improving undernutrition with its processors by incorporating groundnut into children's food.

In Nigeria Engagement of community-based seed producers increased the supply of quality seeds of improved varieties in the remote areas. Through this arrangement, a large number of farmers were reached. Resource-poor farmers are ready to 
adopt new improved varieties if they possess traits the end-user wants. An efficient seed system for delivering varieties must be linked to the commodity value chain. The developed grain markets are an obvious driver of seed demand through which the need for production is justified. The multi-stakeholders approach enhanced efficiency and effectiveness to reach this goal. The IPs ranked inadequate capital as the most important constraint and inadequate credit facilities as the major constraints to seed production. This implied that, resource-poor farmers could not purchase quality production inputs, pay for labor and efficient postharvest operations. As such, using smaller seed packs as a marketing approach with engagement of private seed companies in MSPs has helped reach hundreds of thousands of farmers quickly, including women. The sale of small packs has helped to expand the use of certified seeds. It has also given farmers the opportunity to experiment with new varieties at minimum risk.

In Ethiopia The National Chickpea Innovation Platform identified major actors and enabled whole system understanding of the sector, where gaps are identified, solutions proposed, and responsibilities shared, and action taken. In general, the platform played a significant role in supporting the sector and improving the productivity and production of the crop that in turn improved the livelihood of member farmers and associated communities. Achievements in the area of improving availability of seed through establishing and strengthening the informal seed system can be taken as a game changer success. Moreover, farmers' participatory variety selection (FPVS) approach at the start of intervention built farmers' confidence on improved chickpea technologies and enabled faster and smooth uptake. Demonstrations of technologies selected by the farmers' participation and concomitant farmers' field day visits created awareness and raised interest of wider mass of farmers. Despite the achievements made by the platform in improving the availability, there is still shortage of seed to satisfy the farmers' demand. On the other hand, commitment gaps observed among the members of the platform resulted in limitations in the achievements attained so far. It was also not possible to organize frequent gathering of the platform because of resource limitations. Therefore, in order to sustain and strengthen the platform, extra dedication of the actors and fulfilling its resource requirement are crucial.

In Tanzania The collaboration between research and the private sector in demand creation activities enabled the Tanzania Agricultural Research Institute (TARI) to reach more farmers throughout the country. The operating cost of facilitating the innovation process was lowered as multiple partners were brought on board allocating their own resources to perform some of the activities, e.g. seed production, field days, and monitoring activities. The team only catalyzed the bringing together of stakeholders to pursue their common interests. This is a major step forward compared to many past and recent platform experiences where everything collapses at the end of the initiating project. Use of labor-saving technologies at scale will ben- 
efit other players in the groundnut value chain like processors and manufacturers of farm implements who will fabricate the required equipment.

In India Platform activities were localized within villages in four regions of Uttar Pradesh. Farmers were initially hesitant to the concept of organizing into farmers' seed societies and collaborating in the process of strengthening seed system of chickpea. The cost involved towards membership also influenced the farmer willingness to belong to. However, with continued persuasion of the project team through series of discussion and meetings and matching of their need for quality seed of chickpea, farmers organized themselves into formal seed societies. The existing social dynamics influenced the process of group mobilization with incidences of preferences for a particular social group within villages. The registered farmers' seed societies indirectly worked towards developing group bonding and facilitated farmer-to-farmer exchange of information related to improved agricultural technologies and seed among the group members. The formal structure of the societies also facilitated member farmers in communicating their perceptions on chickpea production technologies with the project team and other agencies. The member farmers attached social prestige to their membership to the seed societies and to their contribution for improving the chickpea seed availability-unfortunately, these efforts were confined to village level meaning such need to be replicated in thousands of villages for this system to leave a mark at national level.

\subsection{Conclusions and Way Forward}

The key highlights emerging from looking at these eleven cases across seven countries are the fact that smallholder farmers in all these countries face very narrow windows of opportunity and the net benefits that they can capture from agricultural technologies are marginal at individual scale. Taking Ethiopia as a representative example, the average farm size in the TL III project study areas was about 2.24 ha. The average total land holding for the upper $25 \%$ of the sampled households is about 4.1 ha of which 3.8 ha is cultivated land and 0.5 ha is fallow land. For the lowest $25 \%$ of the households, the average land holding is just 0.6 ha of which the share of fallow land is nil. The average share of land under chickpea is 0.38 ha (Asfaw and Shiferaw 2009). This situation is typical of legumes farming in almost all project countries. Whereas at country level the margins resulting from improved agricultural technologies are surmountable, at individual level many smallholder farmers may not appreciate the change because of their very small farm sizes and for this reason some are hesitant to make changes to embrace improved technologies. Another important missing factor noticed in all cases is the partnership business model. The business model is likely the most critical component for sustainability and should be the basis for which the partnership on the innovation platform is built. This business model should also be adapted over time to ensure that all partners are really benefiting in ways that make their own delivery more 
effective and efficient. Finally, the IP should build in capacity development mechanisms to continuously strengthen the core actors. This is the glue that holds them together.

\section{References}

Asfaw S, Shiferaw B (2009) Baseline assessment of groundnut, chickpea and pigeonpea for Eastern and Southern Africa. ICRISAT, Patancheru, India, p 32

Dixit, G. P, Srivastava, A. K, Singh, N. P. (2019) Marching towards self-sufficiency in chickpea. Curr. Sci. 116, 239-242. https://doi.org/10.18520/cs/v116/i2/239-242

Gowda CLL, Ojiewo C, Ganga Rao NVPR, Silim SN, Monyo ES, Siambi M (2014) Unlocking opportunities in African pulses production through public-private partnerships. In: A handbook on minor and imported pulses of India-2014. International Crops Research Institute for the Semi-Arid Tropics (ICRISAT), Patancheru, India

Kassie M, Shiferaw B, Asfaw S, Abate T, Muricho G, Teklewold H, Eshete M, Assefa K (2010) Current situation and future outlooks of the chickpea sub-sector in Ethiopia. Working Paper. ICRISAT, Nairobi, Kenya

McGuire S, Sperling L (2016) Seed systems smallholder farmers' use. Food Security 8:179-195. https://doi.org/10.1007/s12571-015-0528-8

Ndjeunga J, Arega A, Katungi E, Mausch K, Charyulu K, Coulibaly O, Bantilan C, Ahmed B, Zarafi MA, Cisse Y, Suhasini K, Rashid AM, Behura D (2016) Enhancing market opportunities, policies and partnerships along the legume value chain to increase the income and nutritional security of smallholder farmers in drought-prone areas of sub-Saharan Africa and South Asia. In: Monyo ES, Varshney RK (eds) Seven seasons of learning and engaging smallholder farmers in the drought-prone areas of sub-Saharan Africa and South Asia through Tropical Legumes, 2007-2014. International Crops Research Institute for the Semi-Arid Tropics, Patancheru, India, p 236

Ngwenya H, Hagmann J (2011) Making innovation systems work in practice: experiences in developing and facilitating innovation platforms. Knowledge Management for Development Journal 7:109-126. https://doi.org/10.1080/19474199.2011.593867

Rohrback DD, Minde IJ, Howard J (2003) Looking beyond national boundaries; regional harmonization of seed policies, laws and regulations. Food Policy 28:317-333

Rubyogo JC, Akpo E, Omoigui Monyo ES, Ojiewo C (2019) Market-led options to scale up legume seeds in developing countries: experiences from the tropical legumes project. Plant Breed 138(4):474-486. https://doi.org/10.1111/pbr.12732

Open Access This chapter is licensed under the terms of the Creative Commons Attribution 4.0 International License (http://creativecommons.org/licenses/by/4.0/), which permits use, sharing, adaptation, distribution and reproduction in any medium or format, as long as you give appropriate credit to the original author(s) and the source, provide a link to the Creative Commons license and indicate if changes were made.

The images or other third party material in this chapter are included in the chapter's Creative Commons license, unless indicated otherwise in a credit line to the material. If material is not included in the chapter's Creative Commons license and your intended use is not permitted by statutory regulation or exceeds the permitted use, you will need to obtain permission directly from the copyright holder.

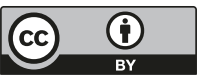

